\title{
Fidelização de associados: Uma análise a partir das transações efetuadas
}

\author{
Loyalty of cooperative members: An analysis based on transacted sales \\ Fidelización de asociados: Un análisis a partir de las transacciones hechas
}

Recebido: 01/03/2021 | Revisado: 07/03/2021 | Aceito: 13/05/2021 | Publicado: 01/06/2021

\author{
Aline Ardenghi Flôr \\ ORCID: https://orcid.org/0000-0003-3072-4328 \\ Universidade Federal de Santa Maria, Brasil \\ E-mail: alineardenghiflor@hotmail.com \\ Mariele Boscardin \\ ORCID: https://orcid.org/0000-0002-3308-4189 \\ Universidade Federal de Santa Maria, Brasil \\ E-mail:marieleboscardin@ hotmail.com \\ Luiz Carlos Zucatto \\ ORCID: https://orcid.org/0000-0003-0731-9180 \\ Universidade Federal de Santa Maria, Brasil \\ E-mail: luiszucatto@gmail.com \\ Adriano Lago \\ ORCID: https://orcid.org/0000-0002-0499-102X \\ Universidade Federal de Santa Maria, Brasil \\ E-mail: adrianolago@yahoo.com.br \\ Luciana Fagundes Christofari \\ ORCID: https://orcid.org/0000-0002-7637-3423 \\ Universidade Federal de Santa Maria, Brasil \\ E-mail: luciana_christofari@ufsm.br
}

\begin{abstract}
Resumo
A fidelidade dos associados é fator crucial para que a cooperativa se desenvolva e proporcione a seu quadro social condições de manutenção e desenvolvimento. Nesta perspectiva as transações comerciais entre cooperativa e cooperado refletem parte da interação entre estes dois agentes. Este trabalho se propôs investigar a participação econômica dos cooperados em uma cooperativa agropecuária do Rio Grande do Sul, por meio de pesquisas documentais, coleta de dados das transações dos cooperados. Com os dados coletados foram realizadas análises estatísticas descritivas e multivariadas. A partir das análises multivariadas observou-se a formação de três grupos de associados: o grupo 1 representado pelo maior número de sócios, e com os menores volumes de negócios; o grupo 2 apresenta maior volume de transação de insumos; o grupo 3 é representado pelo menor número de sócios, porém com maior importância comercial, e com volumes maiores de faturamentos e depósitos. Essa diferenciação permite a cooperativa identificar o perfil dos associados e as áreas de transações mais atrativas para os diferentes grupos dentro da cooperativa.
\end{abstract}

Palavras-chave: Cooperativas; Transações; Participação.

\begin{abstract}
Member loyalty is a crucial factor for the development of a cooperative, and it also provides members with conditions for maintenance and development. Considering this, the commercial transactions between the cooperative and its members reflect part of the interaction between them. This study aimed to investigate the economic participation of members of an agricultural cooperative in Rio Grande do Sul, Brazil, through documentary research consisting of data collection of the members' transactions. Descriptive and multivariate statistical analyses were performed. The multivariate analyses showed the formation of three groups of associates. Group 1 represented the largest number of members and the lowest volume of business; group 2 included the most transactions of agricultural inputs; and group 3 represented the smallest number of members but with the greatest commercial importance and the highest volumes of invoicing and deposits. This differentiation allows the cooperative to identify the members' profile and the most attractive transaction areas for different groups within the cooperative.
\end{abstract}

Keywords: Cooperatives; Transactions; Participation.

\section{Resumen}

La fidelidad de los asociados es factor crucial para que la cooperativa se desarrolle y proporcione a su cuadro social condiciones de mantenimiento y desarrollo. En esta perspectiva las transacciones comerciales entre cooperativa y asociado demuestran parte de la interacción entre estos dos agentes. Este trabajo se propuso investigar la participación económica de los asociados en una cooperativa agropecuaria de Rio Grande do Sul, a través de pesquisa documental, colecta de datos de las transacciones de los asociados. Con los datos colectados fueran realizadas análisis estadísticos, 
descriptivos y multivariados. A partir de los análisis multivariados se observó la formación de tres grupos de asociados: el grupo 1 representado por el mayor número de socios y con los menores volúmenes de negocios; el grupo 2 presenta el mayor volumen de transacción de insumos; el grupo 3 es representado por el menor números de asociados pero con mayor importancia comercial y con volúmenes mayores de facturación y depósitos. Esa diferenciación permite a la cooperativa identificar el perfil de los asociados y las áreas de transacciones más atractivas para los diferentes grupos dentro de la cooperativa.

Palabras clave: Cooperativas; Transacciones; Participación.

\section{Introdução}

Historicamente, as cooperativas apresentam sua configuração através de arranjos coletivos e de atuações diretas às necessidades de seus sócios. Mais especificamente no setor agropecuário, ao longo do tempo, essas organizações propiciaram benefícios a seus associados, tais como assistência técnica, fornecimento de insumos, armazenamento, industrialização, comercialização de produtos, e fornecimento de crédito (Ferreira \& Arbage; 2015). Através destes, as cooperativas veem se consolidando em diversas cadeias agroindustriais, como um agente de relevante expressão.

De acordo com dados da Organização das Cooperativas Brasileiras - OCB (2018), as cooperativas estão presentes em mais de 100 países, congregam mais de 1 bilhão de pessoas, geram cerca de 250 milhões de empregos, existem 2,6 milhões de cooperativas em nível mundial, onde 1 a cada 7 pessoas no mundo são associadas a cooperativa, além de constatar que se as trezentas maiores cooperativas do mundo fossem um país, elas seriam a $9^{\mathrm{a}}$ economia mundial.

Enquanto ente jurídico, a cooperativa possui algumas peculiaridades, como o regime jurídico próprio. Nesta perspectiva, destaca-se na Lei ${ }^{\circ} 5764 / 71$, o artigo $4^{\circ}$ que caracteriza as cooperativas como "sociedades de pessoas, com forma e natureza jurídica próprias, de natureza civil, não sujeitas à falência, constituídas para prestar serviços aos associados". A mesma lei também retrata a cooperativa como a "união de pessoas para o exercício de uma atividade econômica, de proveito comum, sem objetivo de lucro" (Brasil, 1971).

É consenso que as cooperativas são organizações criadas com o intuito de prestação de serviço para seus sócios, portanto, pode-se dizer que essas são ativos específicos para que sejam realizadas transações para com seus associados. São vastos os argumentos que explicitam a relevância social e econômica das cooperativas agropecuárias no âmbito do agronegócio brasileiro, particularmente do estado do Rio Grande do Sul.

Porém, com sua inserção em um ambiente de competitividade, decorrente da globalização de mercados, as cooperativas agropecuárias, em sua maioria, apresentam dificuldades para se adequarem à competitividade dinâmica imposta pelo mercado. Levando-as a enfrentarem desde a redução do apoio recebido por produtores, redução das margens de lucro, até a exclusão dos cooperados e das cooperativas que não se adéquam a este meio (Jerônimo, 2006).

Inserida nesse contexto, a cooperativa agropecuária analisada, está localizada no Médio Alto Uruguai, região Noroeste do estado do Rio Grande do Sul, a qual encontra-se inserida em uma perspectiva ampla para desenvolver-se na sua região de atuação, pelo fornecimento de insumos, recebimento, industrialização e comercialização de produtos oriundos de médios e pequenos produtores rurais cooperados.

Diante dessa situação emerge a seguinte questão: Quais são as características das transações mais frequentemente realizadas na cooperativa, e o perfil dos associados que as realizam? Para responder essa questão, definiu-se como objetivo geral, investigar a participação econômica dos associados da Cooperativa Agropecuária de Produção e Comercialização de Jaboticaba LTDA - COOPERJAB. Como objetivos específicos, definiu-se; caracterizar o perfil dos sócios da cooperativa; identificar os setores de comercialização mais importantes; avaliar a existência de características em comum entre os grupos de sócios analisados; avaliar a participação econômica dos associados; e caracterizar quais transações ocorrem mais frequentes na cooperativa. 
É consenso na literatura a importância da temática da fidelidade, porém, são poucos os estudos recentes que envolvam esse tema. Justificando-se desta maneira a importância das investigações das razões que determinam os associados para realizarem a entrega ou não de sua produção para a unidade da cooperativa.

\section{Fidelidade e Cooperativismo Agropecuário.}

Estudos realizados demonstram que as cooperativas apresentam a capacidade de melhorar a qualidade de vida da população em suas regiões de atuação. Essas organizações, na busca de seus objetivos, indireta ou diretamente, trabalham direcionadas à promoção do desenvolvimento sustentado da comunidade regional ou local. Essa é uma maneira de promoção do desenvolvimento, o qual possibilita que surjam comunidades mais sustentáveis, com a capacidade de suprir as suas necessidades imediatas, despertando ou descobrindo suas vocações locais, desenvolvendo suas potencialidades especificas, e propiciando o fomento ao intercâmbio externo.

Entre as diversas formas de organizações que poderiam impulsionar e proporcionar o desenvolvimento endógeno ou local, em uma determinada comunidade, destacam-se as cooperativas. De acordo com Silva, Alves e Rocha Jr. (2008), as organizações cooperativas são entidades que têm a capacidade de promover o desenvolvimento local, sendo que trabalham em favor da comunidade na qual atuam, buscando agregação de valor a seus sócios.

Turra, Santos e Colturato (2002), relatam que diante do trabalho cooperativo, as pessoas começam a descobrir e desenvolver seus potenciais, atitudes e valores, contribuindo para a melhoria da qualidade de vida. É notável que inúmeras experiências cooperativistas, proporcionam o desenvolvimento social e humano dos indivíduos por meio da coletividade, sendo que é um processo baseado no abandono da individualidade, e a internalização dos valores do trabalho coletivo. É necessário também estabelecer o equilíbrio, entre a gestão social e a gestão empresarial, por intermédio de investimentos em políticas públicas ou projetos sociais.

Segundo Morais (2014), quando se discute sobre desenvolvimento local, é necessário compreender as necessidades, e tirar proveito das potencialidades que cada ator local apresenta, com a finalidade da promoção de melhorias na qualidade de vida para todos. De acordo com Buarque (1999), o desenvolvimento sustentável local se idealiza como uma nova maneira de promoção do desenvolvimento.

Segundo autores como Bandeira (1999) e Buarque (1999), as organizações cooperativas, oferecem a oportunidade de evitar os intermediários, o que proporciona a retenção dos recursos para a comunidade em que estão inseridas, caso contrário, esses valores seriam exportados para outras regiões, por empresas centralizadoras de capital. Esses valores gerados são agregados à renda dos indivíduos, melhorando a qualidade de vida da população e contribuindo para o crescimento da região, produzindo, desta forma, verdadeiramente uma mutação social.

As cooperativas do setor agropecuário vêm ocupando no agronegócio brasileiro, um lugar de destaque quando se trata de números expressivos relacionados ao volume comercializado da produção, empregos gerados, exportação de produtos, e número de associados. De acordo com os dados do Ministério da Agricultura Pecuária e Abastecimento - MAPA (2018), o agronegócio no ano de 2017 no Brasil foi responsável por 24\% do PIB. As exportações totais do agronegócio brasileiro do ano de 2016 atingiram a marca de mais de US\$ 84 bilhões, o volume das exportações agroindustriais e agropecuárias bateu um novo recorde, terminando 2016 com 170 milhões de toneladas, valor 4\% superior ao ano de 2015, de acordo com MAPA (2017).

Em conformidade com os aspectos econômicos e sociais, o setor cooperativo, se consolida como um sistema com capacidade de inclusão social e geração de renda, congregando uma população de mais de 1 bilhão de pessoas. De acordo com Waack e Machado (1999), tão grande quanto o número de cooperados são os números dos crescentes desafios que o setor 
enfrenta para sobreviver neste novo ambiente de competição, e preservar sua fidelidade no cumprimento dos seus princípios doutrinários.

Bialoskorski Neto (2002) relata que, independente de um grande número de cooperativas terem foco no trabalho social, quem determina um bom desempenho social das cooperativas é a sua eficiência econômica. Fato este que pode ser avaliado por diversas variáveis financeiras-econômicas, como posse de terras igualitárias, nível de renda de associados, dentre outras. Neste sentido, o desempenho de mercado e o desempenho econômico, são condições fundamentais para se obter um bom rendimento em nível social para as cooperativas.

De acordo com Giarola et al. (2012), é essencial para a solidez financeira da cooperativa, que essa estabeleça estratégias com a finalidade de fidelizar seus sócios. Giarola (2011) afirma que os desvios de produções que são praticados pelos sócios, é um crítico problema, tratando-se, principalmente, de cooperativas do setor agropecuário, além deste, sofrem também com a oscilação de preço em períodos de safra e entressafra.

Com a baixa ou inexistente fidelidade, por parte dos cooperados para com sua cooperativa, essa deixa de ter sentido em sua existência e também compromete sua eficiência de escala e operacional, ficando em desvantagem perante seu segmento de atuação, refletindo na diminuição da oferta de benefícios aos sócios.

Nilsson, Svendsen e Svendsen (2012), afirmam que cada vez mais os sócios estão abandonando suas cooperativas, encarecendo o seu sistema de manutenção, já que obtêm um volume menor de negócios, fato que cria um círculo vicioso. Assim, quanto menos sócios fiéis, a capacidade de oferecer serviços de maior qualidade reduz e os associados restantes inclinam-se, também, a deixar a cooperativa. E quando a insatisfação aumenta, a dificuldade de reverter o caso é maior. Segundo Boehlje, Akridge e Downey (1995), um fato determinante para essa situação é o aumento da competição entre empresas e cooperativas

Os trabalhos relacionados à gestão e manutenção da fidelidade de cooperados se intensificaram nos últimos vinte anos, principalmente em decorrência das mudanças no ambiente concorrencial. Neste âmbito, os elevados níveis de competitividade tornaram-se importantes condições para a obtenção da perenidade das cooperativas. Para a realização deste objetivo, uma das alternativas encontradas para enfrentar estas variáveis, se volta para o estabelecimento de relacionamentos duradouros com os associados (Berry, 1983; Reicheld, 1996; Whiteley, 1996).

Como método de análise da fidelidade dos associados de cooperativas, segundo a literatura observa-se uma grande quantidade de trabalhos sob a ótica da participação econômica relacionada principalmente à entrega de produtos, e/ou questionários para avaliar a fidelidade dos sócios (Maraschin, 2004; Móglia, Parada Júnior, Bialoskorski Neto \& Marchi, 2004; Rosalem \& Silva, 2009; Simioni, Siqueira, Binotto; Spers \& Araujo, 2009; Giarola, 2011; Melesko, 2012; Rossés, Tomazi, Stecca, Oliveira \& Sccott, 2015). Contrapondo aos trabalhos existentes a presente pesquisa avalia a fidelidade sobre uma nova ótica, que são as transações, tanto de compra quanto de venda, realizadas pelos associados. Ainda como diferencial, o recorte da amostra analisada neste estudo ocorre em função da participação social na cooperativa em estudo.

\section{Metodologia}

A pesquisa foi realizada na Cooperativa Agropecuária de Produção e Comercialização de Jaboticaba LTDA COOPERJAB, localizada no município de Jaboticaba, situada no noroeste do estado do Rio Grade do Sul - Brasil. Utilizou-se o estudo de caso como estratégia de pesquisa. Segundo Yin (2001), o estudo de caso auxilia na compreensão e interpretação dos fenômenos individuais, coletivos, organizacionais, políticos e sociais, além de permitir uma investigação com o intuito de preservar as características, dos eventos ocorridos na vida real e também na sua totalidade. Com base nessas afirmações é importante ressaltar a importância econômica e social que a COOPERJAB apresenta para a região que está inserida, bem como seu papel de regulador de mercado. 
De acordo com Cellard (2008), a pesquisa documental pode ser considerada um testemunho único das atividades em particular que ocorreram em um passado recente. Ainda de acordo ao mesmo autor, a pesquisa documental se justifica, por acrescentar à compreensão social a dimensão de tempo. Conforme Oliveira (2007), a pesquisa documental se incumbe de analisar documentos que não sofreram ainda tratamento analítico, ou seja, documentos de fontes primárias. A pesquisa documental foi realizada nas atas das assembleias gerais ordinárias e nos livros de presença das mesmas (dos anos de 2010 a 2016) e no balanço de contas do ano contábil (2016).

A pesquisa foi pautada nos métodos qualitativos e quantitativos. Sendo que o método qualitativo buscou identificar a existência das interações sociais, sendo estas baseadas na confiança, e que são responsáveis por dar origem ao capital social das cooperativas agrícolas (Creswell, 2010). Entretanto também foram utilizados na pesquisa dados socioeconômicos, que contextualizaram e caracterizaram os cooperados, sendo assim, a pesquisa utilizou dados quantitativos para estes fins.

Portanto a pesquisa se enquadrou em um método misto, que de acordo com Creswell (2010), se baseia em uma abordagem investigativa, a qual associa ou combina as formas quantitativas e qualitativas, através da inserção no ambiente natural da pesquisa, ou seja, inserindo-se no ambiente dos produtores rurais, realizando pessoalmente a coleta de dados, e também das múltiplas fontes de onde os dados serão obtidos (documentos como atas e livros de presenças em assembleias gerais ordinárias, etc.).

A pesquisa documental foi realizada nas atas das assembleias gerais ordinárias e nos livros de presença das mesmas (dos anos de 2010 a 2016) e no balanço de contas do último ano contábil (2016), de acordo com Cellard (2008), esses documentos podem ser considerados um testemunho único das atividades em particular que ocorreram em um passado recente.

Para a realização da coleta de dados foram considerados dois aspectos relevantes para o cooperativismo: a participação econômica e a participação social dos produtores rurais associados à cooperativa. Dentre os critérios de seleção dos associados que foram analisados, estão: (1) terem realizado sua associação na cooperativa antes do ano de 2010; (2) os sócios devem apresentar movimentações financeiras com a cooperativa tanto de compra quanto de venda de produtos no período relativos aos anos de 2010 a 2016; (3) terem participado de, pelo menos, uma assembleia geral ordinária no período de 2010 a 2016.

A cooperativa em estudo apresenta um total de 480 associados, totalizando uma média anual de associações de 19 novos sócios. Do total de associados, a participação em assembleias gerais ordinárias entre os anos de 2010 a 2016 apresentou uma média de 68 associados, o que representa $14 \%$ do seu quadro social. É importante ressaltar que dos 480 associados atualmente, 302 se associaram antes do ano de 2009, e 178 após o ano de 2009, ou seja, 37\% passaram a compor o quadro social nos últimos nove anos. Desse total de associados que compõem a cooperativa, 96 participaram ao menos de uma assembleia geral ordinária no período estudado, e 52 sócios participaram de no mínimo três assembleias gerais ordinárias.

Quando se analisam as movimentações financeiras realizadas com a cooperativa durante os anos de 2010 a 2016, encontram-se apenas 98 associados que realizaram compra e venda de produtos com a cooperativa. Para a amostra foram selecionados os associados que além de realizar a compra e venda de produto na cooperativa, participaram de pelo menos uma assembleia geral ordinária no período de 2010 a 2016, ou seja, 96 associados.

Os dados coletados foram divididos em setores, para as compras realizadas na cooperativa: compra de insumos; compra na agropecuária; compra de rações; e, compras no supermercado. Esses valores também serão anuais referentes ao período de análise. No que concerne à entrega de produtos, foram coletados dados anuais de acordo ao período em análise, com quantidades em quilogramas dos principais produtos agrícolas (soja, trigo e milho), depositados na cooperativa por seus sócios. No setor de faturamento foram coletados dados anuais referentes ao período de análise, constando os produtos faturados no período, o preço médio anual de vendas, e a receita total obtida com o faturamento de cada produto. Esses dados foram sistematizados em planilhas do Microsoft Excel $^{\circledR}$ para posterior análise. 
Com a finalidade de caracterizar os associados quanto às variáveis estudadas (agropecuária, mercado, ração, insumos, depósito de soja $(\mathrm{Kg})$, faturamento da soja $(\mathrm{kg})$, depósito do milho $(\mathrm{kg})$, faturamento do milho $(\mathrm{kg})$, depósito do trigo $(\mathrm{kg})$, faturamento do trigo $(\mathrm{kg})$, total depositado $(\mathrm{Kg})$, e total faturado $(\mathrm{kg})$ ) realizou-se a análise de componentes principais (PROC PRINCOMP do SAS), utilizando a matriz de correlação para as médias das variáveis entre os anos de 2010 a 2016, para cada associado. Foram obtidos os componentes principais com seus autovalores e autovetores, bem como o gráfico biplot, no qual são apresentadas observações e as variáveis conjuntamente, como orienta Gabriel (1971). Na sequência, realizou-se a análise de agrupamento (PROC CLUSTER do SAS), por meio do método da mediana e objetivando formar grupos de associados com características afins. A partir do dendrograma, 3 grupos evidentes foram escolhidos à distância 0.75 para distância mediana. Outros métodos também foram testados, mas o método acima citado foi o que reduziu a percentagem de observações mal classificadas nos seus respectivos grupos nas análises subsequentes, e por isso foi escolhido.

Posteriormente, as diferenças entre os grupos foram estudadas por meio de análise discriminante canônica e comparações univariadas entre as variáveis. Para realizar a análise discriminante canônica, duas pressuposições devem ser atendidas: normalidade multivariada e homogeneidade dentro de matrizes de covariância. Normalidade multivariada foi testada por meio do teste de Mardia (Macro \%Multinorm do SAS) (Mardia, 1970; 1975), porém os dados não apresentaram normalidade. $\mathrm{O}$ teste de homogeneidade de matrizes de covariância foi testado utilizando o teste $\mathrm{M}$ de Box, que apresentou matrizes de covariância heterogêneas (PROC DISCRIM do SAS). Desta forma, aplicou-se o método não linear discriminante (PROC DISCRIM do SAS) e verificou-se a percentagem total de observações mal classificadas dentro dos grupos, sendo que apenas $4.17 \%$ das observações estavam sendo mal classificadas. Como a percentagem de observações mal classificadas foi pequena, optou-se por seguir com a análise discriminante canônica, como sugerido por Fernandez (2002). A análise discriminante canônica iniciou com a identificação das variáveis mais influentes na diferenciação dos grupos (PROC STEPDISC do SAS) e, posteriormente, com a obtenção dos coeficientes para as variáveis originais dentro das variáveis canônicas e a obtenção do gráfico que mostra a distância entre os grupos formados (PROC CANDISC do SAS).

Por fim, foram realizadas análises de comparações entre os grupos para cada variável. Como muitas variáveis não apresentavam normalidade optou-se por utilizar o método não paramétrico de Kruskal-Wallis e as comparações múltiplas por meio do método de Dwass, Steel, Critchlow-Fligner (DSCF), quando o p-valor foi significativo. Para essa situação, como as variáveis não apresentavam normalidade, a mediana foi utilizada como medida de tendência central, seguida pelo intervalo interquartil que possibilita a percepção da variabilidade dos dados. Todas as análises foram realizadas no software SAS Unversity Edition (SAS Institute, 2012). Significância estatística foi considerada ao nível de 5\% (0.05) de probabilidade.

\section{Resultados e Discussão}

Quando se fala em cooperação e participação de associados, podem ser realizadas análises de diferentes maneiras sobre o assunto, primeiro pode-se considerar o cooperativismo como sendo uma forma de solidariedade e voluntarismo pelos associados, em segundo a análise de cooperação pela ótica da participação econômica, no qual o cooperativismo vem decorrente da consequente necessidade de evolução econômica que está intrínseca nestas organizações (Bialoskorski Neto, 2007).

Sendo que a discussão sobre a participação de sócios em cooperativas pode ser realizada desde a fase pela qual as cooperativas se formaram através de uma importante coalizão dos interesses coletivos, por um grupo solidário e voluntário, até a parte que se refere a necessidade da participação econômica para alavancar o crescimento, impulsionar o mercado, e consequente internalização da lógica de maximizar resultados (Bialoskorski Neto, 2004; Soares, 1984). 
Segundo Eschenburg (1983), a escola de Munster explica que as organizações cooperativas devem existir através de parâmetros solidários somente em um primeiro momento, posteriormente deve-se estabelecer um processo no qual o sucesso da cooperação somente ocorre se o benefício econômico obtido for maior do que este alcançaria de maneira autônoma.

Ferreira (2014) ressalta que a baixa participação dos associados em assembleias, e nas suas instâncias decisórias, é um novo desafio a ser superado pelas organizações cooperativas. Pois, a gestão democrática que deve se estabelecer, necessita da participação do maior número possível de associados participantes. Pois sem a participação do quadro social, fica impossível que as decisões tomadas representem a vontade do coletivo. O mesmo autor também destaca que essa baixa adesão às assembleias, podem decorrer da confiança dos sócios para com sua cooperativa, pois estes veem na mesma um baixo risco financeiro, o que os motiva a não participação. Também retrata que o baixo capital que os associados têm na cooperativa, propiciam a baixa participação e também ações oportunistas oriundas dos sócios.

Em outra linha de argumentos referentes à participação dos cooperados, Bialoskorski Neto (2007), ao estudar dezesseis cooperativas, consideradas mais importantes do estado do Paraná, confirma a hipótese de que, quanto maior e melhor for o desempenho econômico, maior é o incentivo à redução da participação do quadro social nas estruturas cooperativas. Isso sugere que exista uma relação inversamente proporcional em relação ao desempenho econômico e à participação social dos cooperados nas assembleias gerais ordinárias. Essa constatação sinaliza que na proporção que o associado tem a percepção de que a cooperativa está em uma condição financeira favorável, ocorre o afastamento do mesmo nos processos de tomada de decisão.

A Figura 1 retrata o faturamento e as sobras das transações realizadas pela cooperativa em estudo, no período de 2010 a 2016. Observa-se um acréscimo anual, tanto no faturamento quanto nas sobras, evidenciando a condição financeira favorável da mesma, e a participação cada vez maior dos associados em transações com a cooperativa. Vale ressaltar que no ano de 2015, como observa-se na figura, mesmo com o aumento do faturamento as sobras no final do período decrescem. Esse fator é explicado de acordo com o balanço contábil da cooperativa, pela perda no valor aproximado de $\mathrm{R} \$ 550.000,00$, por conta da recuperação judicial de uma empresa, que a cooperativa comercializa soja, que decretou recuperação fiscal naquele ano.

Figura 1: Faturamento e sobras dos anos de 2010 a 2017.

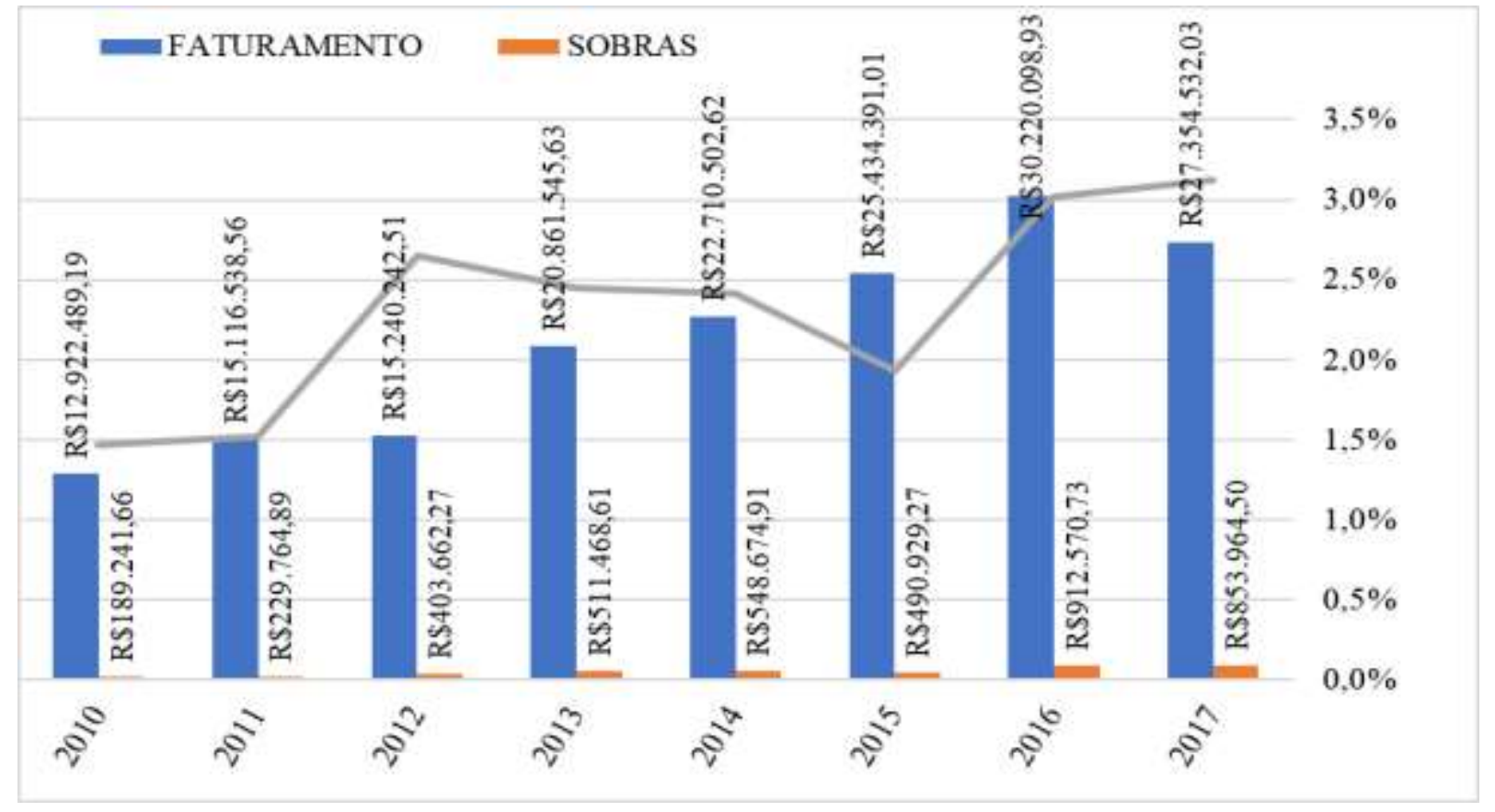

Fonte: Elaborado pela autora, dados COOPERJAB (2017). 
De acordo com a análise documental realizada na Cooperativa Agropecuária de Produção e Comercialização de Jaboticaba LTDA, em relação à participação dos associados em Assembleias Gerais Ordinárias (AGO's), identificaram-se os percentuais, como descrito: no ano de 2010 observou-se uma participação de 6,66\%, em 2011 participação de 13,54\%, em 2012 participação de 12,29\%, em 2013 participação de 19,79\%, em 2014 participação de 18,75\%, em 2015 participação de 14,58\% e em 2016 participação de 14,37\%. Estes valores se alinham àqueles do estudo de Ferreira (2014) e com as afirmações de Bialoskorski Neto (2007), para o qual a participação nas AGO's é inversamente proporcional ao número de associados.

Segundo Moreira (2006), a ideia de fidelização e de participação dos associados, parte do pressuposto que este, se sinta parte ativa da cooperativa, de que tudo é feito e realizado pensando no associado, e em sua satisfação. Assim, quando este tem a percepção da qualidade do serviço e produtos oferecidos se tornará um disseminador de aspectos positivos, proporcionando sócios fiéis, fazendo com que os indecisos se convençam das vantagens da lealdade junto à cooperativa.

Estas constatações são corroboradas pelo Relatório Expressão do Cooperativismo Gaúcho 2017, ano base 2016. Neste relatório evidencia-se que, apesar da crise econômica do país, no setor cooperativo agropecuário houve um crescimento de 14,22\% na comparação entre 2016 e 2015, retratando um faturamento de $\mathrm{R} \$ 41,2$ bilhões. Ainda segundo o relatório, os dirigentes afirmam que este fato se dá pelo poder de crescimento do setor em tempos difíceis, sendo este um combustível para a união das pessoas. Destaca-se, também, um crescimento de $76 \%$ em novos ingressos no setor nos últimos cinco anos. Também é importante ressaltar que o setor agropecuário ocupa a segunda colocação no estado dos ramos cooperativos de maior crescimento com 14,51\%, e primeiro lugar em faturamento com um aumento nos últimos cinco anos de $34,60 \%$ (OCERGS/SESCOOP, 2017).

Segundo Knapp (2015), ao se analisar os demonstrativos contábeis da COTRIROSA, observou-se um crescimento no faturamento da mesma em proporções significativas: no período de 2009 a 2014 o faturamento geral da cooperativa cresceu $155,23 \%$, resultado semelhante ao encontrado na COOPERJAB. Também foi observado na COTRIROSA em relação às sobras e/ou perdas do período, que se evidencia o aumento das sobras no período.

É importante ressaltar que com relação à política de sobras adotadas pelas cooperativas, Ferreira (2014) observou que existem diferentes formas de distribuição, sendo que algumas distribuem esse valor diretamente na transação, enquanto outras o fazem no final do período de exercício. $O$ valor relativo às sobras se fazem importantes para que a cooperativa possa realizar novos investimentos e se capitalizar, sendo que a partir das sobras se capitalizam os fundos de reserva obrigatórios. Ainda segundo esse autor, pode-se observar que, em média, o percentual de sobras distribuídas aos associados é de 20\%. Este parâmetro está em acordo com o observado na cooperativa em estudo, na qual as sobras são distribuídas aos sócios no final do exercício na proporção de $20 \%$. Vale ressaltar que, as sobras são relativas as movimentações realizadas pelos sócios, quanto mais o mesmo transaciona maior o valor relativo a sobras terá o direto de receber no final do período.

$\mathrm{Na}$ cooperativa em estudo, quando se estratificam os valores faturados e sobras no ano de 2016, constata-se a expressiva participação que o setor de insumos e grãos apresenta para os resultados positivos obtidos pela cooperativa, conforme a Figura 2. 
Figura 2: Faturamento e sobras do ano de 2016 dividida por setores.

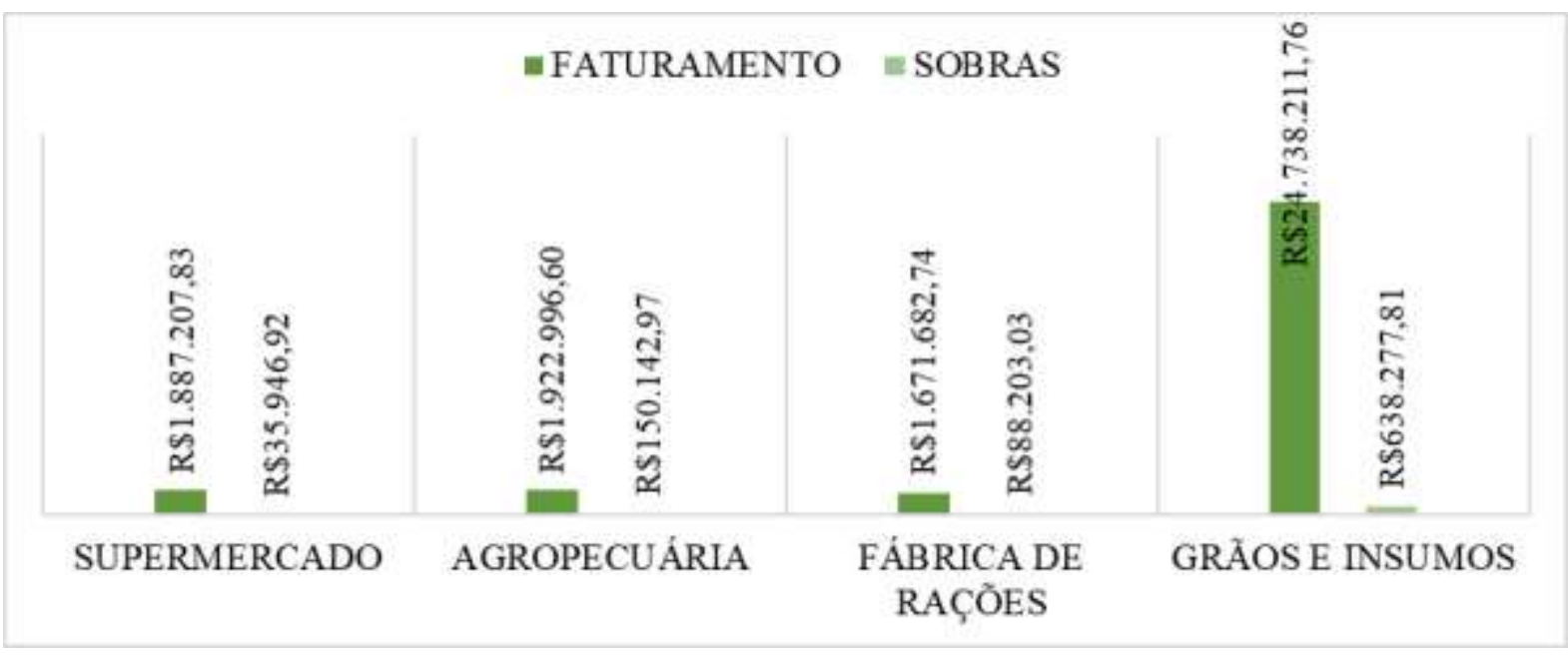

Fonte: Elaborado pela autora, dados COOPERJAB (2017).

O setor de grãos e insumos contempla $81,86 \%$ das movimentaç̃es e do faturamento da cooperativa, podendo ser considerado o carro-chefe da organização, seguido pelo setor leiteiro, composto pela fábrica de rações (5,53\%) e da agropecuária (6,36\%). Contudo, quando analisamos as sobras, o setor leiteiro (fábrica de rações e agropecuária) contribue com aproximadamente $26 \%$ do total gerado, ficando atrás ainda do setor de grãos e insumos (69,94\%). O supermercado além de uma baixa expressão no total faturado (6,24\%) também apresenta uma baixa contribuição nas sobras $(3,93 \%)$, entretanto, além da diversificação dos negócios da cooperativa também exerce um papel social perante a comunidade em geral, tendo em vista que não atende apenas os sócios.

Cabe ressaltar que o percentual anual de composição do faturamento e das sobras é variável. Por exemplo: no ano de 2010 a relação da participação de cada setor nas sobras da cooperativa foi de 58\% de grãos e insumos; 25\% supermercado; 17\% agropecuária. Já em 2016, os resultados foram: 70\% grãos e insumos; 16\% agropecuária; $10 \%$ fábrica de raçoes; e 4\% supermercado.

Levando em consideração que a fábrica de rações iniciou suas atividades no ano de 2015, apresenta-se um comparativo entre os valores obtidos das sobras do período de 2016. Fica evidente a drástica redução da participação do supermercado no faturamento da cooperativa, sendo que no ano de 2010 era responsável por $25 \%$ das sobras, reduzindo esse valor para somente $4 \%$ no ano de 2016. A participação da agropecuária pode ser considerada constante, sem oscilações significativas de participação nas sobras. E no ano de 2016, um ano após o início do funcionamento da fábrica de rações, essa já representa um total de 10\% de participação nas sobras, evidenciando o potencial de crescimento do setor.

O setor de grão e insumos, que já era responsável pela obtenção das maiores somas, aumentou sua participação relativa, que era de $58 \%$ para $70 \%$, sinalizando o setor como o responsável pela maior parte das movimentações da cooperativa. Esses percentuais são corroborados pelos dados da OCERGS/SESCOOP (2017), que evidencia que as principais cadeias de cooperativas do estado são do segmento de grãos. Estas, também são as cooperativas em maior número no estado, e são responsáveis por $50 \%$ da safra gaúcha da soja.

Knapp (2015) observou que, de maneira semelhante à COOPERJAB, a COTRIROSA, também apresentou no decorrer dos anos em estudo, um acréscimo no percentual de participação dos setores de grão e insumos no faturamento anual da cooperativa, entretanto em contrapartida, a COTRIROSA apresenta um crescimento anual também no setor do supermercado, ao contrário do observado na COOPERJAB que sinaliza um decréscimo desse setor no faturamento da mesma. 
Quando realizada a análise de componentes principais, feita a partir da matriz de correlação, o primeiro componente explicou $37 \%$ da variação total dos dados, enquanto o segundo componente explicou $17 \%$. Conjuntamente, os dois primeiros componentes explicaram 54\% da variação total dos dados apresentados na Tabela 1, valor que pode ser considerado satisfatório para a realização destas análises.

O primeiro componente representa a relação inversa entre insumos $(0,38)$, total depositado $(0,34)$ e total faturado $(0,34)$ versus faturamento em soja $(-0,35)$ e agropecuária $(-0,342)$. Verificando que os mesmos associados que realizam mais movimentações com compras de insumos, também são os que apresentam quantidades de produtos faturados e depositados em maior proporção, evidenciando que o grupo que mais fatura tende a comprar mais insumos e em menores proporções realizam transações em outros setores (agropecuária, supermercado, rações, por exemplo). Também é possível evidenciar que a cooperativa pratica mais frequentemente a comercialização de grãos de trigo e milho, sendo a soja um produto mais competitivo pelo mercado e nas disputas de preços.

Em contrapartida os mesmos associados que mais compram insumos e faturam grãos, apresentam relação inversa entre as compras na agropecuária o que pode ser explicado pela diferenciação do seu ramo de atuação que não condiz com os itens que são comercializadas na mesma (produtos em geral para animais). Entretanto, para explicar o baixo faturamento de soja, observa-se que ocorrem grandes transferências de produtos entre produtores, seja para pagamento de arrendamentos, ou trabalham em sociedade, e/ou são pai e filho (s) conduzindo o mesmo negócio, ou/e como já mencionado logo acima a concorrência pode apresentar preços mais competitivos, ou a espera de melhores condições de mercado.

Tabela 1. Autovetores e autovalores da análise de componentes principais, realizada a partir da matriz de correlação e considerando as médias de cada associado no período de 2010 a 2016 para as variáveis estudadas.

\begin{tabular}{lcc}
\hline \multirow{2}{*}{ Variáveis } & \multicolumn{2}{c}{ Autovetores } \\
& Componente principal 1 & Componente Principal 2 \\
\hline Agropecuária & $\mathbf{- 0 . 3 4 2}$ & -0.101 \\
Mercado & -0.274 & -0.192 \\
Ração & -0.144 & -0.049 \\
Insumos & $\mathbf{0 . 3 7 8}$ & 0.184 \\
Depósito de soja $(\mathrm{kg})$ & -0.201 & $\mathbf{0 . 4 6 6}$ \\
Faturamento de soja $(\mathrm{kg})$ & $\mathbf{- 0 . 3 5 3}$ & $\mathbf{0 . 3 0 3}$ \\
Depósito de milho $(\mathrm{kg})$ & 0.151 & $\mathbf{- 0 . 5 4 3}$ \\
Faturamento de milho $(\mathrm{kg})$ & 0.254 & $\mathbf{- 0 . 4 0 9}$ \\
Depósito de trigo $(\mathrm{kg})$ & 0.269 & 0.137 \\
Faturamento de trigo $(\mathrm{kg})$ & 0.286 & 0.099 \\
Total depositado $(\mathrm{kg})$ & $\mathbf{0 . 3 4 1}$ & 0.234 \\
Total faturado $(\mathrm{kg})$ & $\mathbf{0 . 3 4 0}$ & 0.242 \\
\hline Autovalores & 4.858 & 2.166 \\
\hline Proporção & $\mathbf{0 . 3 7 4}$ & $\mathbf{0 . 1 6 7}$ \\
Proporção cumulativa & 0.374 & $\mathbf{0 . 5 4 0}$ \\
\hline
\end{tabular}

Fonte: Elaborado pela autora a partir de dados da COOPERJAB (2017).

O segundo componente representa a relação inversa entre deposito de soja $(0,466)$ e faturamento de soja $(0,353)$ versus depósito de milho $(-0,543)$ e faturamento de milho $(-0,409)$, também segundo a Tabela 1 . Isso pode estar relacionado a 
época de plantio das culturas, pois a maioria dos associados da cooperativa em estudo possuem pouca área de terra (média de 50 hectares por associado segundo COOPERJAB, (2017)), realizando o plantio anual de apenas uma destas culturas na maior parte dos casos.

Pois, no que tange à época de plantio, segundo Jacto (2018) o período recomendado para o plantio do milho na região Sul do Brasil é no mês de agosto, com sua colheita nos meses de dezembro a junho, a soja em período normal deve ser plantada no mês de setembro e sua colheita realizada nos meses de janeiro a maio. Euzébio (2018) relata que a safrinha de milho pode ser realizada normalmente após a colheita da soja precoce, no período que compreende janeiro a março, com a colheita no período de abril e junho. Ainda de acordo com a mesma autora, o período da safrinha irá ocorrer no final da janela de plantio recomendada, afetando diretamente a produtividade dessas culturas, pois nesses períodos ocorre elevação nos riscos de incidência de geadas, secas e fotoperíodo limitado no final do ciclo das culturas.

A Figura 3 apresenta graficamente a análise dos componentes principais das variáveis estudadas. Cada quadrante traz as observações com características em comum. Ressalta-se que quanto mais próxima a observação está dos eixos (x ou y) mais próxima da média para as variáveis analisadas.

Figura 3. Dendograma obtido por meio da análise de componentes principais das variáveis estudadas.

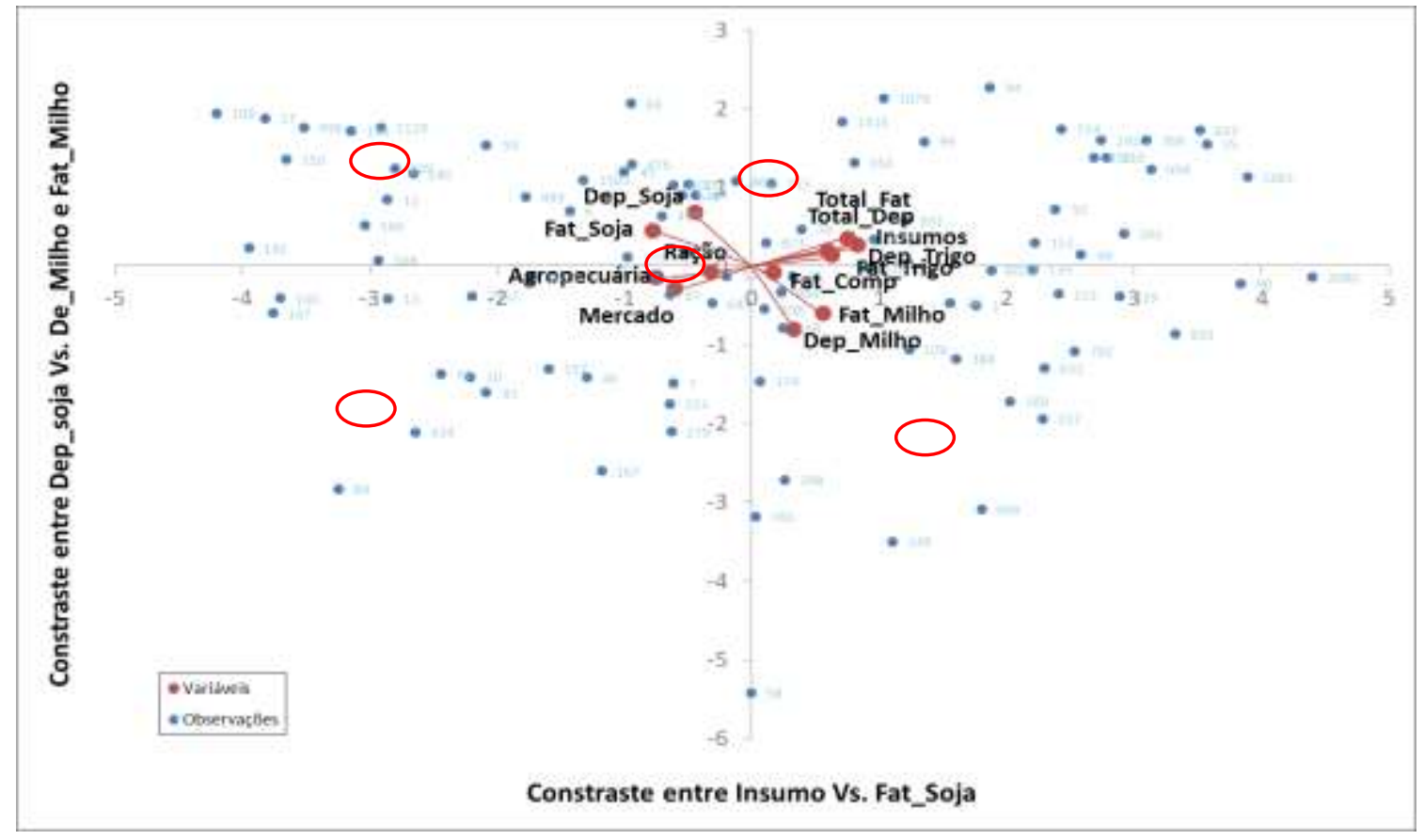

Fonte: Elaborado pela autora, dados COOPERJAB (2017).

Para os associados enquadrados no quadrante superior direito, as observações que estão nesse quadrante apresentam valores altos de insumos e depósito de trigo e baixos de faturamento de soja, depósito de milho e faturamento de milho (exemplo, associado $n^{\circ}$ 163). Este grupo de associados realiza a compra de insumos na cooperativa em estudo, porém não faz a entrega da safra e, consequentemente, o faturamento da mesma, em ressalva da safra de trigo.

Segundo o superintendente da Organização das Cooperativas Brasileiras em entrevista à revista Globo Rural (2018), na compra de insumos ou venda de produtos, as cooperativas brasileiras vêm servindo como balizadoras de preços, lembrando que o maior desafio é o de manter o equilíbrio entre remunerar bem os produtores rurais e conseguir insumos com menores custos. De acordo com o Sistema Ocepar (2018a), através do levantamento realizado pela Embrapa Trigo, observou-se que as 
cooperativas participantes das capacitações em convenio com a OCB são responsáveis por $60 \%$ do trigo produzido no país, congregando $85 \%$ dos produtores deste cereal.

Para associados que se enquadraram no quadrante superior esquerdo, as observações que estão nesse quadrante apresentam valores altos de faturamento de soja e depósito de soja e baixos de insumo, depósito de milho e faturamento de milho (exemplo, associado $n^{\circ} 59$ ). Essas evidências sugerem que esse grupo de associados faz a entrega da safra de soja na cooperativa, e seu faturamento, não realiza a compra de insumos para realizar o plantio da lavoura na cooperativa. Também se observa que esse mesmo grupo não realiza o plantio de milho nesse período pelo conflito de épocas de plantio e/ou pelo custo de plantio da mesma e, consequentemente, não realiza a entrega e faturamento da mesma na cooperativa.

De acordo com o Globo Rural (2018), se faz importante ressaltar que as cooperativas brasileiras exportaram no ano de 2017, 20,07\% a mais que no ano anterior, sendo o complexo da soja responsável por 28\% deste total. A Revista News (2018), retrata que a safra de soja do ano de 2018/2019 deve ter um aumento de área plantada de 2,30\%, comparada à safra anterior, a cultura do milho em grão surpreende com uma expressiva elevação de 5,53\% na expectativa de área a ser cultivada na safra 2018/2019. O Sistema Ocepar (2018b), relata que a soja apresenta uma liquidez muito mais elevada que a cultura do milho, sendo que o produtor rural não irá sacrificar as áreas de plantio de soja para realizar plantio de milho no verão.

Em relação ao quadrante inferior esquerdo, as observações que estão nesse quadrante apresentam valores altos de faturamento de soja, depósito de milho e faturamento de milho e baixos de insumos e depósito de soja (exemplo, associado $\mathrm{n}^{\circ}$ 10). Pode-se inferir que os associados que se enquadram nessa observação não costumam realizar a compra de insumos na cooperativa, realizam o depósito e faturamento de milho, e realizam o faturamento e não o depósito de soja, por que essa soja é oriunda de transferências entre os associados, ou faturamento da safra anterior (a cooperativa não determina um período limite para que os grãos fiquem depositados na mesma, sem serem faturados).

Segundo o Sistema Ocepar (2018b), o fato da elevação da área plantada de milho é atípico levando em consideração as séries históricas da cultura, entretanto se faz expressiva pelo fato de que em algumas áreas brasileiras a rentabilidade do grão de milho ter superado a soja, em função dos bons preços de comercialização do mesmo. De acordo com a mesma fonte, a margem operacional da safra de milho do estado do Paraná, está estimada em R $\$ 2.853,00$ por hectare, enquanto a margem operacional da soja está calculada em R \$ 1.155,00. Ressalta-se, contudo, que em comparação à safra 2017/18, a margem operacional do milho 2018/19 é quase três vezes maior ( $\mathrm{R} \$ 1.023,00)$.

Diante dos resultados encontrados no banco de dados da cooperativa, também foi possível evidenciar que do total de produtos depositados na cooperativa, $87 \%$ é faturado no mesmo período. Já, do total depositado observam-se os seguintes valores: $45 \%$ de soja; $42 \%$ de milho e $13 \%$ de trigo. E do total faturado os valores foram de: $47 \%$ de soja; $39 \%$ de milho e $14 \%$ de trigo.

No que se refere ao quadrante inferior direito, as observações que estão nesse quadrante apresentam valores altos de insumos, depósito de milho e faturamento de milho e baixos de faturamento de soja e depósito de soja (exemplo, associado ${ }^{\circ}$ 160), revelando que os associados que realizam a compra de insumos depositam e faturam suas safras de milho na cooperativa, ao contrário dos produtores da soja.

Segundo o Sistema Ocepar (2018b), no estado do Rio Grande do Sul, a média de preço de venda de grão de milho é praticada quase $70 \%$ a mais ( $\mathrm{R} \$ 37,00)$ do que em relação ao mesmo período do ano anterior, exemplificando a expressiva variação que o preço do milho sofre no mercado. Por outro lado, a soja apresenta uma variação pequena em relação a seu preço de comercialização. Segundo a revista O Presente (2018), essa variação foi de apenas $10 \%$ em relação ao mesmo período do ano de 2017. Entretanto, algumas unidades armazenadoras da soja estão trabalhando com estoque máximo, ou seja, o produtor está postergando o faturamento do produto que fica estocado nessas unidades, podendo comprometer a logística das safras que estão por vir. 
Levando em consideração todas essas observações, pode-se concluir que todos os setores analisados da cooperativa são importantes, o que varia é o perfil de cada cooperado para se encaixar em determinado segmento. Além disso, para o grupo estudado, os setores da agropecuária e supermercado, apresentam caráter mais social do que de grandes negócios, pois os volumes das transações são inferiores aos demais.

No estudo realizado por Maraschin (2004), na bacia leiteira da região de Santa Rosa - RS pode-se observar a importância do setor leiteiro para a cooperativa analisada, sendo que os mesmos produtores que entregavam o leite para a cooperativa também eram responsáveis por entregar aproximadamente $30 \%$ do milho e do trigo e $40 \%$ da soja recebidas pela cooperativa, observando uma tendência de que os produtores de leite que entregam leite para a cooperativa, também transacionem com a mesma nos demais setores agrícolas.

A Tabela 2 apresenta a estatística descritiva dos principais grãos comercializados pela cooperativa (média, mediana, máximo e mínimo). Observou-se discrepância entre volume de entrega de grãos entre os associados da cooperativa, o que pode ser explicado pela disparidade das propriedades dos mesmos. Os valores de máximo e mínimo são extremos, onde se tem tanto produtores que não produzem ou não depositam sua produção na cooperativa, quanto, produtores com volume expressivo de produção. A Tabela 2 também apresenta as variáveis que proporcionaram a formação de três grupos distintos pela análise discriminante canônica (método 'stepwise'). Vale ressaltar que a produção de trigo apresenta mediana zero, pois a maior parte dos produtores pesquisados não realiza o plantio da cultura, ou não comercializa está com a cooperativa.

Tabela 2: Estatísticas descritivas das médias das transações efetuadas pelos associados amostrados da COOPERJAB nos anos de 2010 a 2016 (dados de depósito de grãos) e análise discriminante das variáveis determinantes para a diferenciação dos grupos e seus respectivos parâmetros estatísticos.

\begin{tabular}{llll}
\hline Medidas & Depósito de soja & Depósito de milho & Depósito de trigo \\
\hline Média & $28.422,20 \mathrm{~kg}$ & $27.484,17 \mathrm{~kg}$ & $8.327,81 \mathrm{~kg}$ \\
Mediana & $8.139,50 \mathrm{~kg}$ & $4.018,00$ & $0,00 \mathrm{~kg}$ \\
Mínimo & $0,00 \mathrm{~kg}$ & $0,00 \mathrm{~kg}$ & $0,00 \mathrm{~kg}$ \\
Máximo & $857.733,00 \mathrm{~kg}$ & $697.170,00 \mathrm{~kg}$ & $225.751,00 \mathrm{~kg}$ \\
\hline Variáveis & $\mathbf{R}^{2}$-parcial & Correlação Canônica Quadrada Média & P-valor \\
\hline Total faturado & 0.9096 & 0.454782 & $<.0001$ \\
Total depositado & 0.1417 & 0.505373 & $<.0001$ \\
Insumos & 0.1330 & 0.528915 & $<.0001$ \\
\hline
\end{tabular}

Fonte: Elaborado pela autora, dados COOPERJAB (2017).

Considerando os dados de área plantada e produção de soja, milho e trigo para o município de Jaboticaba - RS disponíveis no IBGE CIDADES (2016) referentes ao ano de 2016, a COOPERJAB, recebeu no ano de 2016: 42,83\% do total de soja, $52,37 \%$ do milho e $74,95 \%$ da produção de trigo no município. Neste sentido, é possível afirmar que a cooperativa em questão absorve um percentual significativamente alto das principais culturas produzidas pelo município. Além do fato da geração de renda para o próprio município por meio da arrecadação de impostos e tributos, que retornam para o mesmo na forma de investimentos em saúde, educação, infraestrutura, agricultura, dentre outros.

A Figura 4 apresenta a análise de agrupamentos, realizada a partir das variáveis estudadas, evidenciando a formação de três grupos distintos. As principais variáveis relacionadas à diferenciação do grupo um e dois são mercado, ração, faturamento de soja $(\mathrm{kg})$ e faturamento de milho $(\mathrm{kg})$, pois apresentaram os maiores coeficientes na variável canônica 1 . As 
principais variáveis que estão relacionadas na diferenciação do grupo dois e três são faturamento de soja $(\mathrm{kg})$, faturamento de milho $(\mathrm{kg})$ e depósito de trigo $(\mathrm{kg})$, pois apresentaram os maiores coeficientes na variável canônica 2 . A diferença univariada entre os grupos será analisada na sequência.

Figura 4. Grupos formados pela análise de agrupamento e sua distância a partir da análise discriminante canônica.

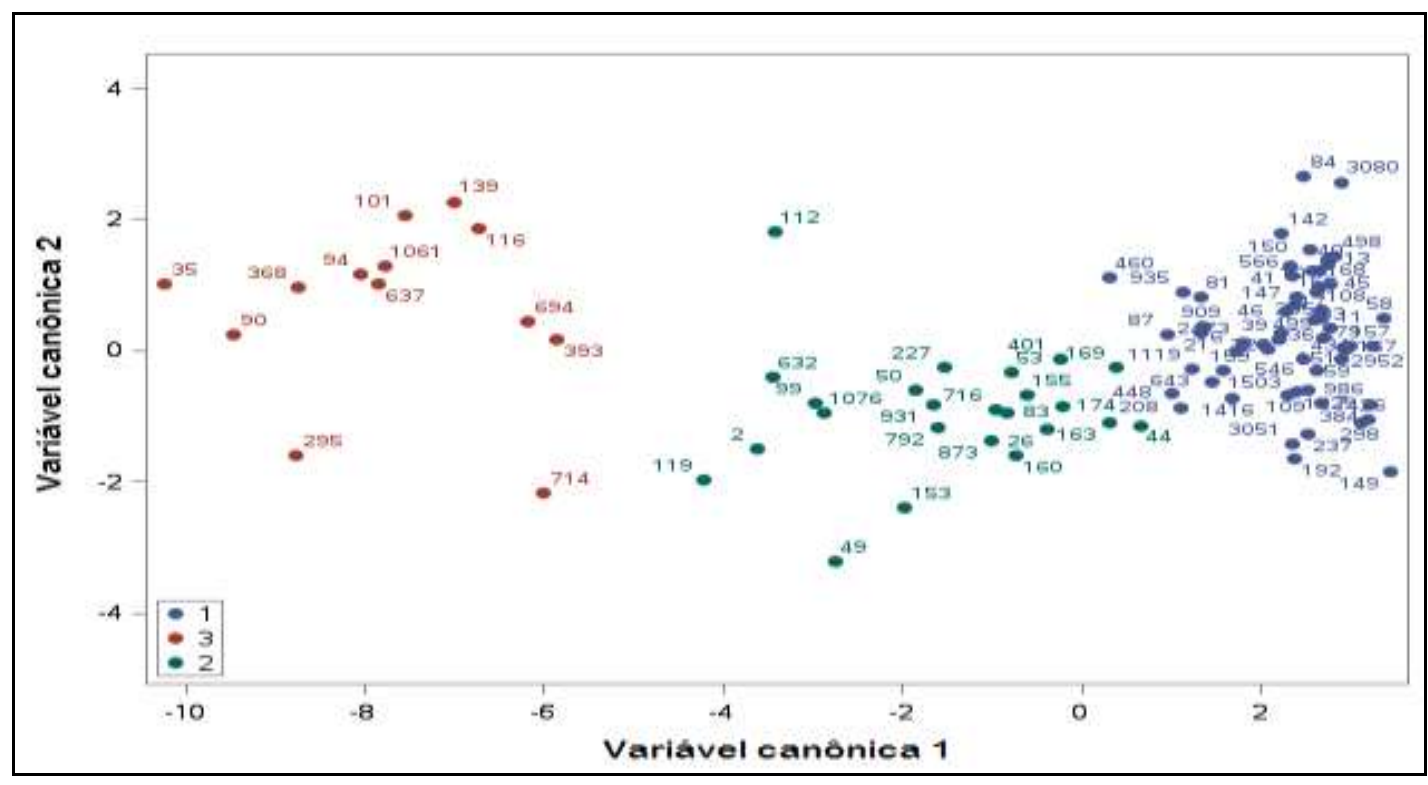

Fonte: Elaborado pela autora, dados COOPERJAB (2017).

Pode-se observar estatisticamente a diferença entre os grupos para cada variável analisada (Tabela 3). Onde as letras indicam as diferenças entre os grupos quando existentes. Nota-se, ainda, que o grupo um engloba a maioria dos associados (64), seguido pelo grupo dois no qual se tem 19 associados, e o grupo três apresenta 13 associados. A importância de cada variável varia em relação ao grupo analisado, sendo que cada grupo se caracteriza por essa diferenciação. 
Tabela 3. Medianas e intervalo interquartis dos grupos para as variáveis estudadas utilizando o teste não paramétrico de Kruskal-Wallis.

\begin{tabular}{lllll}
\hline \multirow{2}{*}{ Variáveis } & \multicolumn{2}{l}{ Mediana (intervalo interquartil) } & P-valor \\
\cline { 2 - 4 } & Grupo 1 & Grupo 2 & Grupo 3 & \\
\hline Agropecuária (\%) & $20.3(16.0) \mathrm{A}$ & $7.2(7.4) \mathrm{B}$ & $4.0(4.9) \mathrm{B}$ & $<\mathbf{0 . 0 0 0 1}$ \\
Mercado (\%) & $13.8(22.6) \mathrm{A}$ & $5.6(5.8) \mathrm{B}$ & $3.9(5.2) \mathrm{B}$ & $<\mathbf{0 . 0 0 0 1}$ \\
Ração (\%) & $0.0(3.6)$ & $0.3(1.9)$ & $0.0(0.03)$ & 0.2086 \\
Insumos (\%) & $59.8(43.3) \mathrm{B}$ & $86.3(19.4) \mathrm{A}$ & $91.4(4.8) \mathrm{A}$ & $<\mathbf{0 . 0 0 0 1}$ \\
Dep. soja (\%) & $52.6(36.9)$ & $39.1(19.9)$ & $47.0(12.9)$ & 0.3757 \\
Fat. Soja (\%) & $66.7(39.6) \mathrm{A}$ & $42.2(26.4) \mathrm{B}$ & $41.1(11.9) \mathrm{B}$ & $\mathbf{0 . 0 0 0 2}$ \\
Dep. Milho (\%) & $38.4(34.9)$ & $43.7(19.4)$ & $37.3(3.5)$ & 0.5685 \\
Fat. Milho (\%) & $22.6(33.6) \mathrm{B}$ & $41.7(26.7) \mathrm{A}$ & $35.2(11.9) \mathrm{AB}$ & $\mathbf{0 . 0 0 4 1}$ \\
Dep. Trigo (\%) & $0.0(5.9) \mathrm{B}$ & $10.1(13.1) \mathrm{A}$ & $13.3(5.4) \mathrm{A}$ & $<\mathbf{0 . 0 0 0 1}$ \\
Fat. Trigo (\%) & $0.0(10.1) \mathrm{B}$ & $10.7(8.4) \mathrm{A}$ & $15.1(9.5) \mathrm{A}$ & $<\mathbf{0 . 0 0 0 1}$ \\
Total depósito (kg) & $84096.5(144088) \mathrm{C}$ & $670758(215668) \mathrm{B}$ & $1274191(238395.3) \mathrm{A}$ & $<\mathbf{0 . 0 0 0 1}$ \\
Total faturado $(\mathrm{kg})$ & $68130.2(144848) \mathrm{C}$ & $546477(258317.3) \mathrm{B}$ & $1176572(108684) \mathrm{A}$ & $<\mathbf{0 . 0 0 0 1}$ \\
\hline No Observações & 64 & 19 & 13 & \\
\hline
\end{tabular}

Fonte: Elaborado pela autora, dados COOPERJAB (2017).

Para o grupo um, o qual apresenta a maior parte do grupo de associados analisados, as variáveis que os diferenciam dos demais, são os valores maiores em compras na agropecuária, mercado e faturamento de soja (kg). Entretanto, vale ressaltar que estes associados transacionam com todos os setores, porém com menor proporção. Pode-se evidenciar que o grupo 1 apresenta um volume individual de negócios em menor proporção que os demais grupos.

O grupo dois possui características semelhantes ao grupo três, representado pelo maior volume de transações nos setores de insumos, faturamento de milho, depósito e faturamento de trigo. O grupo dois possui valores intermediários dos demais grupos em relação a quantidade total de produtos depositados e faturados.

O grupo três, representado pelo menor número de associados (13), apresenta relativamente a maior importância comercial dentre os demais, pois apresentam os valores mais significativos em relação ao volume total faturado e o depositado na cooperativa. Também é expressivo na compra de insumos, depósito e faturamento de trigo. Essas observações evidenciam a disparidade de poder aquisitivo entre os associados da cooperativa, onde um grande grupo de associados (grupo um), em relação ao valor e volume comercializado é menos expressivo que ao grupo três o qual é representado por um pequeno grupo de associados.

Contudo, pode-se observar a formação de grupos distintos de associados, com características particulares, verificou-se no primeiro grupo que é composto pelo maior número de associados que os mesmos realizam transações mais frequentemente na agropecuária e supermercado diferente dos demais grupos, o segundo grupo se assemelha ao terceiro grupo, com número de sócios intermediários dos demais grupos, e com maior número de transações de compra de insumos, o terceiro grupo, formado pelo menor número de associados, representa a maior importância comercial dentre os três grupos, com os maiores volumes de transações. 


\section{Conclusão}

A importância social é indiscutivelmente expressiva nos três grupos analisados, ou seja, socialmente todos os associados são valorosos e somam para a manutenção e continuidade dos serviços da organização cooperativa. Da mesma forma que todos os setores de serviços da cooperativa são importantes, para os diferentes grupos de associados que a compõe.

A análise aplicada permitiu a divisão deste grupo de sócios em três grupos, referentes a suas características comuns, sendo que o grupo um se destaca do grupo dois pela superioridade nas transações nos setores de rações, supermercado, faturamento de soja, e faturamento de milho. Já o grupo dois se diferencia do grupo três, pelas variáveis de faturamento de soja, faturamento de milho, e deposito de trigo, e o grupo três se apresenta com os maiores valores de transações.

A diferenciação dos produtores através da formação de grupos tem expressiva importância para a cooperativa, para o reconhecimento do perfil de seus cooperados, tanto em relação a conhecer o perfil do quadro social em relação as suas transações de compra e venda de produtos, quanto para reconhecer de maneira mais eficiente os pontos estratégicos de comercialização da cooperativa.

Entre os anos de 2010 a 2016, houve crescimento no faturamento e nas sobras da cooperativa, sendo o setor de grãos e insumos responsável pela maior parte desses resultados. Evidenciou-se que os mesmos sócios que realizam a maior parte da compra de insumos, também apresentam os maiores valores em depósito de grão e faturamento dos mesmos, entretanto, realiza poucas transações com os outros setores da cooperativa como supermercado e agropecuária. A cooperativa absorve $42,83 \%$ da safra de soja produzida no município, $52,37 \%$ da safra de milho e $74,95 \%$ da safra de trigo.

Embora os resultados deste trabalho tratem de uma amostra limitada, entende-se a importância das cooperativas nas comunidades locais e regionais, possibilitando ao associado diferenciações no momento de vender seus produtos e nas aquisições realizadas na própria cooperativa. Algumas transações, mesmo não tendo uma importância econômica relevante, fidelizam o associado. Neste sentido, pesquisas que envolvam o tema de fidelização e o que é capaz de gerá-la a curto, médio e longo prazo tendem a fortalecer as cooperativas existentes.

\section{Referências}

Bandeira, P. S. (1999) Participação, articulação de atores sociais no desenvolvimento regional. Instituto de Pesquisa Econômica Aplicada, Texto para discussão no 630 (ISSN 1415-4765). http://www.ipea.gov.br/agencia/images/stories/PDFs/TDs/td_0630.pdf

Berry, L. (1983) Relationships Marketing. In Emerging perspectives on services marketing (pp. 25-80). American Marketing Association, Chicago.

Bialoskorski Neto S. (2002). Estratégias e cooperativas agropecuárias: um ensaio analítico. In Braga, M. J. \& Reis, B. S. (Org). Agronegócio cooperativo reestruturação e estratégias. Viçosa, 2002.

Bialoskorski Neto, S. (2004). Gobierno y papel de los cuadros directivos en las cooperativas brasileñas: estudio comparativo. Revista de Economía Pública Social y Cooperativa, n. 48.

Bialoskorski Neto, S. (2007). Um ensaio sobre desempenho econômico e participação em cooperativas agropecuária. Revista de Economia e Sociologia Rural, 45(01), 119-138.

Boehlje, M., Akridge, J., \& Downey, D. (1995). Restructuring agribusiness for the 21st century. Agribusiness, 11, $493-500$.

Brasil.(1971). Lei 5764/71, de 16 de dezembro de 1971. Base da Legislação Federal do Brasil, Brasília, DF. http://www.planalto.gov.br/ccivil_03/LEIS/L5764.htm.

Buarque, S. C. (1999). Metodologia de planejamento do desenvolvimento local e municipal sustentável. MEPF/INCRA/IICA.

Cellard, A. (2008) A análise documental. In: Poupart, J. et al. A pesquisa qualitativa: enfoques epistemológicos e metodológicos. Petrópolis, Vozes.

Cooperativa Agropecuária de Produção e Comercialização De Jaboticaba LTDA (COOPERJAB). (2017). Cadastro de associados. Jaboticaba, RS.

Creswell, J. W. Projeto de Pesquisa: Métodos Qualitativo, Quantitativo e Misto. (3 ${ }^{\mathrm{a}}$ ed.): Artmed, 2010.

Eschenburg, R. (1983) Una breve introducción a la teoría económica de la cooperación. Perspectiva Econômica, 13, 7-14.

Euzébio M. P. Época de plantio do Milho. http://folhaagricola.com.br/artigo/epoca-de-plantio-do-milho. 
Fernandez, G. C. J. (2002). Discriminant analysis a powerful classification technique in data mining. Proc. 27th Annu. SAS Users Group Int. Conf. (SUGI), pp. $1-9$

Ferreira, G. M. V. (2014). Governança e sua relação com a fidelidade em cooperativas. Tese de doutorado, Universidade Federal de Santa Maria, Santa Maria, RS, Brasil. 221 p.

Ferreira, G. M. V., \& Arbage, A. P. (2015). Governança e sua relação com a fidelidade em cooperativas agropecuárias. In: Anais do $53^{\circ}$ Congresso da Sociedade Brasileira de Economia, Administração e Sociologia Rural. SOBER.

Gabriel, K. R. (1971). The biplot graphic display of matrices with application to principal component analysis. Biometrika. 58(3), 453-467.

Giarola, E. (2011). A fidelização dos associados nas cooperativas de leite: uma análise sob a perspectiva da Teoria dos Jogos e da Social Network Analysis. In: Anais do ICIEOM 2011 - XVII International Conference on Industrial Engineering and Operations Management, 2011, Belo Horizonte.

Giarola, E., Cristo, P. C. O., Balbino, R. F., Ferreira, R. N., Nazareth, L. G. C., \& Santos, A. C. (2012). A fidelização dos associados nas organizações cooperativistas: uma análise sob a perspectiva da Teoria dos Jogos, Estratégia Empresarial e Governança Corporativa. In: Anais do VII Encontro da Divisão de Estudos Organizacionais da ANPAD - ENEO, 2012, Curitiba.

Globo Rural. (2018). Cooperativas agropecuárias do Brasil faturaram R\$ 200 bilhões em 2017. Economia e negócios. Maio de 2018. https://revistagloborural.globo.com/Noticias/Economia-e-Negocios/noticia/2018/05/cooperativas-agropecuarias-do-brasil-faturaram-r-200-bilhoes-em2017.html.

Instituto Brasileiro de Geografia e Estatística. (2016). IBGE cidades: produção agrícola de lavoura temporária de 2016. https://cidades.ibge.gov.br/brasil/rs/jaboticaba/pesquisa/14/10193.

Jacto. (2018). Calendário agrícola: conheça as melhores épocas para plantar! https://blog.jacto.com.br/calendario-agricola-conheca-as-melhores-epocas-paraplantar/.

Jerônimo F. B. (2006). A gestão estratégica de sociedades cooperativas no cenário concorrencial do agronegócio brasileiro: estudo de caso em uma cooperativa agropecuária gaúcha. Teor. e Evid. Econ. 14(26), 71-89.

Knapp, D. J. (2015). Marketing de relacionamento: a importância para o crescimento e fidelização dos associados da Cooperativa Tritícola Santa Rosa Ltda - Cotrirosa. http://bibliodigital.unijui.edu.br:8080/xmlui/handle/123456789/3080.

Maraschin, A. F. (2004). As relações entre produtores de leite e cooperativas: um estudo de caso na bacia leiteira de Santa Rosa - RS. Dissertação (Mestrado em Desenvolvimento Rural), Universidade Federal do Rio Grande do Sul, Porto Alegre, RS, Brasil.

Mardia, K. V. (1970). Measures of multivariate skewness and kurtosis with applications. Biometrika. 57(3): 519-530. 10.2307/2334770

Mardia, K. V. (1975). Assessment of multinormality and the robustness of Hotelling's T2. Journal of the Royal Statistical Society Series C Applied Statistics; 24(2): $163-171.10 .2307 / 2346563$

Melesko, B. M. (2012). Fidelidade e lealdade: uma relação dos cooperados com sua cooperativa. Monografia (Curso de Pós-Graduação lato sensu em Gestão de Cooperativas da UNIJUí), Universidade Regional do Estado do Rio Grande do Sul, Ijuí, RS, Brasil. http://bibliodigital.unijui.edu.br:8080/xmlui/handle/123456789/556

Ministério da Agricultura, Pecuária e Abastecimento (MAPA). (2017). AGROSTAT - Estatísticas de Comércio Exterior do Agronegócio Brasileiro. http://indicadores.agricultura.gov.br/agrostat/index.htm.

Ministério da Agricultura, Pecuária e Abastecimento (MAPA). (2018). Estatística e dados básicos de economia agrícola. http://www.agricultura.gov.br/.

Móglia, L. C., Parada Júnior, I., Bialoskorski Neto, S., \& Marchi, D. (2004). Fidelidade e reciprocidade do cooperado: o caso da Carol. In: Anais do Congresso da Sociedade Brasileira de Economia, Administração e Sociologia Rural, 42, 2004, Cuiabá: UFMT.

Morais, R. T. R. (2014). Cooperação, cooperativismo e desenvolvimento local: uma relação possível? In: Anais da XIV SIMGeo- Simpósio de Geografia da UDESC. Seminário Nacional de Planejamento e Desenvolvimento.

Moreira, R. R. (2006). O uso da reclamação como meio de coleta de informaçães nas ouvidorias públicas. Dissertação (Mestrado em Ciência da Informação), Universidade de Brasília, Brasília, DF, Brasil.

Nilsson J., Svendsen, G. L. H., \& Svendsen, G. T. (2012). Are Large and Complex Agricultural Cooperatives Losing Their Social Capital? Agribusiness, 28 (2) $187-204$

O Presente. (2018). Safra atípica concentra armazenamento da soja. Março de 2018. https://www.opresente.com.br/geral/safra-atipica-concentraarmazenamento-da-soja/.

Organização das Cooperativas do Brasil (OCB). (2018). O que é Cooperativismo? https://www.ocb.org.br/o-que-e-cooperativismo.

Ocergs/Sescoop. (2017). Expressão do cooperativismo gaúcho 2017: ano base 2016. http://www.sescooprs.coop.br/app/uploads/2017/07/sescooprs-expressaocooperativismo-gaucho-2017.pdf.

Oliveira, M. M. Como fazer pesquisa qualitativa. Petrópolis, Vozes, 2007.

Reicheld, F. F. (1996). A estratégia da lealdade: a força invisível que sustenta crescimento, lucros e valor. Rio de Janeiro, RJ: Campus.

Revista News. (2018). RS: safra do verão 2018/ 2019 tem projeção 34 milhões de toneladas. https://revistanews.com.br/2018/08/28/rs-safra-do-verao-20182019-tem-projecao-34-milhoes-de-toneladas/. 
Research, Society and Development, v. 10, n. 6, e35110613420, 2021

(CC BY 4.0) | ISSN 2525-3409 | DOI: http://dx.doi.org/10.33448/rsd-v10i6.13420

Rosalem, V., \& Silva, E. A. (2009). Gestão de cooperativas: um estudo sob o olhar do cooperado. Revista Administração Pública e Gestão Social. 1(1).

Rossés, G. F., Tomazi, M., Stecca, F. L. P. A., Oliveira, D. C., \& Sccott, C. R. C. (2015). Fidelidade em cooperativa agropecuária: Um estudo de caso. Revista de Gestão e Organizações Cooperativas - RGC, 2(4), 17-34.

Sas Institute (2012). Inc. SAS OnDemand for Academics. Release 9.04.01M5P09132017. SAS Institute Inc., Cary, NC, USA. 2012. https://odamid.oda.sas.com/SASStudio/.

Silva, C. L., Alves, A., \& Rocha Jr. W. F. (2008). Cooperativismo e desenvolvimento no Oeste paranaense: o caso da C. Vale na região de Palotina/PA. Revista de Desenvolvimento Econômico. $\mathrm{n} 18$.

Simioni, F. J., Siqueira, E. S., Binotto, E., Spers, E. E., \& Araujo, Z. A. S. (2009). Lealdade e oportunismo nas cooperativas: desafios e mudanças na gestão. RESR, Piracicaba, SP, 47(03), 739-765.

Sistema Ocepar. (2018a). TRIGO: Embrapa e cooperativas debatem futuro da pós-colheita. Informe Paraná cooperativo. http://www.paranacooperativo.coop.br/ppc/index.php/sistema-ocepar/comunicacao/2011-12-07-11-06-29/ultimas-noticias/119022-trigo-embrapa-ecooperativas-debatem-futuro-da-pos-colheita.

Sistema Ocepar. (2018b). GRÃOS: Milho avança na safra de verão. Informe Paraná cooperativo. http://www.paranacooperativo.coop.br/ppc/index.php/sistema-ocepar/comunicacao/2011-12-07-11-06-29/ultimas-noticias/119321-graos-milho-avanca-nasafra-de-verao.

Soares, R. P. (1984). Sociologia da cooperação: o dilema Meister-Zupanov. Perspectiva Econômica. 45, 91-100.

Turra, F. R., Santos, F. E. De G., \& Colturato, L. C. (2002) Serviço Nacional de Aprendizagem do Cooperativismo: associações e cooperativas. Brasília: [s.n.].

Waack, R. S., \& Machado Filho, C. P. (1999). Administração estratégica em cooperativas agroindustriais. In: Anais do II Workshop Brasileiro de Gestão de Sistemas Agroalimentares - PENSA/FEA/USP - Ribeirão Preto-SP.

Whiteley, R. C. (1996). Crescimento orientado para o cliente: cinco estratégias comprovadas para criar vantagem competitiva. Campus.

Yin, R. K. (2001) Estudo de Caso: Planejamento e métodos. (2ª ed.): Bookman. 